\title{
THE
}

\section{Operating an Acoustic Doppler Current Profiler aboard a Container Vessel}

C. N. Flagg

G. Schwartze

University of Rhode Island

E. Gottlieb

University of Rhode Island

Hans Thomas Rossby

University of Rhode Island, trossby@uri.edu

Follow this and additional works at: https://digitalcommons.uri.edu/gsofacpubs

\section{Citation/Publisher Attribution}

Flagg, C. N., Schwartze, Gottieb, E., \& Rossby, T. (1998). Operating an Acoustic Doppler Current Profiler aboard a Container Vessel. J. Atmos. Oceanic Technol., 15, 257-271. doi: 10.1175/ 1520-0426(1998)0152.0.CO;2.

Available at: https://doi.org/10.1175/1520-0426(1998)015<0257:OAADCP>2.0.C0;2

This Article is brought to you for free and open access by the Graduate School of Oceanography at DigitalCommons@URI. It has been accepted for inclusion in Graduate School of Oceanography Faculty Publications by an authorized administrator of DigitalCommons@URI. For more information, please contact digitalcommons-group@uri.edu. 


\title{
Operating an Acoustic Doppler Current Profiler aboard a Container Vessel
}

\author{
C. N. FLAGG \\ Brookhaven National Laboratory, Upton, New York \\ G. Schwartze, E. Gottlieb, And T. Rossby \\ Graduate School of Oceanography, University of Rhode Island, Narragansett, Rhode Island
}

(Manuscript received 16 August 1996, in final form 10 April 1997)

\section{ABSTRACT}

\begin{abstract}
Since October 1992 an acoustic Doppler current profiler (ADCP) has been in near-continuous operation on board a 118-m-long container vessel, the container motor vessel Oleander, which operates on a weekly schedule between Port Elizabeth, New Jersey, and Hamilton, Bermuda. The ADCP collects information on currents from the surface to depths as great as $404 \mathrm{~m}$ depending on zooplankton concentrations, ship's speed, sea state conditions, and the ship's load factor. The southbound transits provide more and better data because the ship is loaded and rides deeper resulting in less bubble formation and entrainment underneath the vessel.

Installation and operation of an ADCP on a cargo ship has involved a number of factors not typical of research vessels. Providing a data acquisition system that could operate on its own without assistance from the ship's officers and that could recover from problems was the first issue. Isolating and removing electrical transients from the ship's electrical system was extremely challenging. The presence of bubbles underneath the vessel due to variable draft and in heavy weather conditions significantly limits the performance of the ADCP. These difficulties not withstanding, the system is working well and is delivering good data on the southbound legs in most weather conditions and on the northbound legs under more favorable weather conditions. Starting in 1995, differential and attitudinal global positioning system enhancements have made significant improvements to navigational accuracy and ship's heading data.
\end{abstract}

\section{Introduction}

The merchant marine fleet in the North Atlantic is vastly larger than the number of U.S. Navy vessels operating on the high seas and these, in turn, exceed the number of oceanographic research vessels by another order of magnitude. So, in terms of access to the open ocean, commercial shipping offers far more opportunities than research vessels possibly can. Further, merchant marine vessels tend to be in continuous use. Some vessels have equipment for conducting and transmitting routine weather observations, and a subset of these also makes regular measurements of the upper ocean thermal structure using expendable bathythermographs (XBTs). One such vessel is the CMV Oleander, a container vessel that makes weekly trips to Bermuda from Port Elizabeth, New Jersey.

Since 1981 the ship and its predecessor have taken XBT and surface water samples across the continental shelf and slope waters to the Gulf Stream for the Na-

Corresponding author address: Dr. Tom Rossby, Graduate School of Oceanography, University of Rhode Island, Narragansett Bay Campus, Narragansett, RI 02881.

E-mail: tom@rafos.gso.uri.edu tional Marine Fisheries Service on a monthly basis (Benway et al. 1993). At the same time, it also tows a Hardy continuous plankton recorder (CPR) to make underway measurements of zooplankton population densities (Tambs-Lyche 1984). We began to consider the possibility of installing an acoustic Doppler current profiler (ADCP) system to make continuous underway measurements of upper ocean currents along the entire transit, and particularly across the Gulf Stream. When it was learned that a new ship was under construction, we approached the ship operators, Bermuda Container Lines, about the possibility of installing a sea chest in the hull for an ADCP system. The suggestion was received favorably and before the ship was launched, a cofferdam (a sealed-off section) between the hull and hold was constructed, along with the necessary plumbing and conduits for venting and electrical connections. At the ship's first dry-dock period after launch the ADCP's sea chest was installed within the cofferdam.

The energetic variability of the Gulf Stream over a very wide range of timescales is the motivating interest for such a program. It has proved to be very difficult to obtain solid information on the low-frequency (seasonal to interannual) variability of mass and heat transported by the Gulf Stream. The difficulty is that the meandering of the current is so large that single sections 


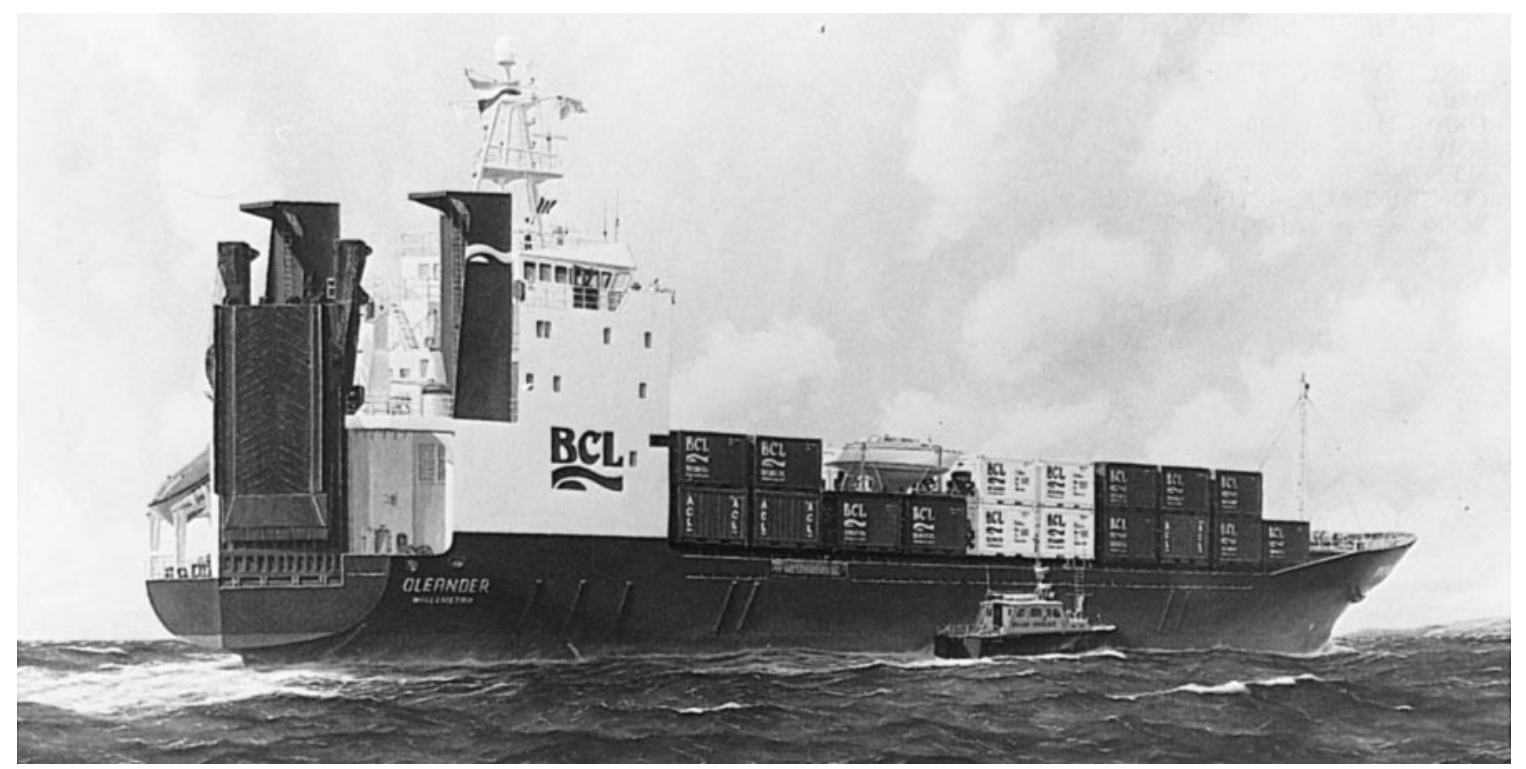

FIG. 1. Artist's view of the CMV Oleander at sea. Specifications are 118.62-m length, 19.8-m breadth, 6.26-m summer draught, 6253 metric ton deadweight, and $8.2 \mathrm{~m} \mathrm{~s}^{-1}$ cruise speed. (Painting by S. J. Card, owned by Bermuda Container Lines Ltd.)

say virtually nothing about underlying long-term mean flows and trends (Iselin 1940; Worthington 1976; Sato and Rossby 1995). One way to overcome the aliasing by the energetic meandering of the current would be to sample the current much more frequently so that the high-frequency fluctuations can be averaged out. The high cost of research vessels precludes their use, so the idea of working with the CMV Oleander stood out as a very attractive alternative. The regular traffic to Bermuda would provide unprecedented and regular sampling of the upper ocean currents along the transit. If such a program could be maintained for several years, it might be possible to separate out oceanic variability spanning a wide range of timescales, that is, from weeks to years. Further, the ship transits several oceanic regimes: the continental shelf, the shelf break, the slope waters, the Gulf Stream, and the northwestern Sargasso Sea, each with its own distinctive characteristics. Finally, the ADCP acoustic backscatter intensity can provide useful information on zooplankton population densities and their spatial and temporal variability (Flagg and Smith 1989).

This paper reports on the installation and operation of the ADCP system onboard the CMV Oleander shown in Fig. 1. The system is working very well, but a large number of technical and software issues had to be resolved along the way, many of which were due to operational differences between research vessels and commercial freighters. We believe it is useful to discuss these difficulties so that they can be anticipated more effectively in future efforts.

The CMV Oleander is a diesel-powered vessel built in 1990 at the Van Der Glessen/De Noord shipyard in the Netherlands and replaces an earlier ship of the same name. The vessel, which has a bulbous bow, is $118 \mathrm{~m}$ long and $20 \mathrm{~m}$ wide with a deadweight of 6250 metric tons. It draws $5.2 \mathrm{~m}$ aft and $0.6 \mathrm{~m}$ less at the bow when fully loaded. These numbers reflect typical conditions during the outbound transits to Bermuda. On the inbound return trips when the ship is lightly loaded, typical draft is $4.8 \mathrm{~m}$ aft and $0.8 \mathrm{~m}$ less at the bow. Figure 2 shows the outline of the vessel. The ship typically steams at about $16 \mathrm{kt}$. Thrust is supplied by a single variable-pitch propeller driven by an in-line eight cylinder $7340 \mathrm{hp}$ diesel engine. Electrical power is provided by diesel generators while in port and from a drive shaft generator at sea. Approximately $2 \mathrm{~h}$ after leaving or before entering port, the electrical service is switched from one system to the other. This switch-over and other surges can cause significant electrical transients that propagate throughout the electrical distribution system.

\section{System description}

The ship's large size, the limitations on ADCP cable lengths, and the need to provide suitable access and environmental protection for the components made it necessary to distribute parts of the ADCP system throughout the ship. The basic components consist of three subsystems, as shown in Fig. 3: 1) computers and support electronics on the bridge, 2) the ADCP deck unit in the engine room, and 3) the narrowband ADCP transducer mounted in a sea chest forward between holds two and three. Multiconductor cable is used to interconnect the subsystems and this has proven to be susceptible to electrical interference, which has been difficult to diagnose and eliminate.

The usual arrangement for shipboard ADCP systems 


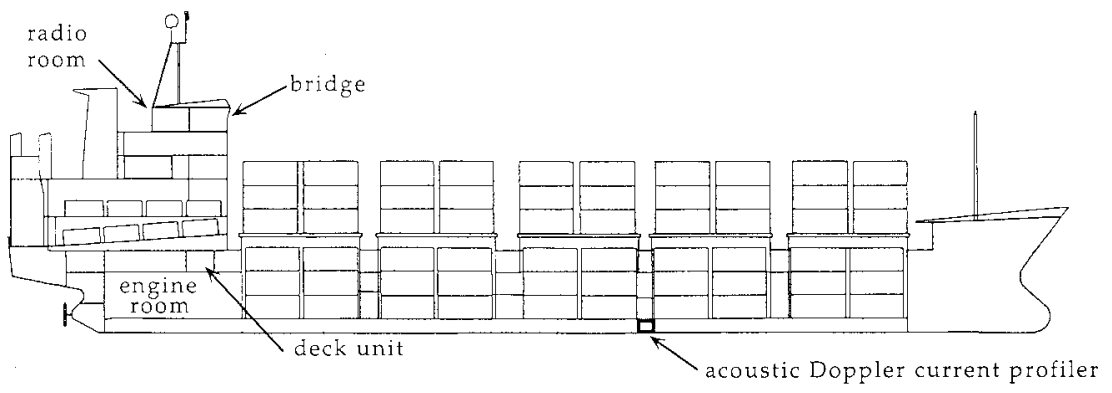

FIG. 2. Schematic view of the CMV Oleander. The ship is flat-bottomed, a characteristic of most container vessels. Shown are the locations of the ADCP transducer and sea chest between holds 2 and 3, the ADCP deck unit in the engine room, and the computers and navigation equipment in the radio room on the bridge.

is to connect both the data acquisition PC and the ship's gyrocompass directly to the deck unit. Usually, the PC to deck unit connection is by a parallel cable, but because of their physical separation we used a serial connection operating at $19.2 \mathrm{kbaud}$. Also, because of severe electrical noise (to be discussed) it was not possible to connect the ship's gyrocompass to the deck unit. This meant that another method was needed to get the ship's heading into the ADCP data stream. This was accom- plished through a software modification to the data acquisition system using a second navigation PC that read, reformatted, and forwarded the heading data by serial line to the main data acquisition PC. A modified version of RD Instruments' DAS 2.48 data acquisition software for narrowband ADCPs, the AutoADCP system, controlled the ADCP operations and data acquisition.

A custom-made desk and cabinet were installed on the bridge in the ship's radio room to accommodate four

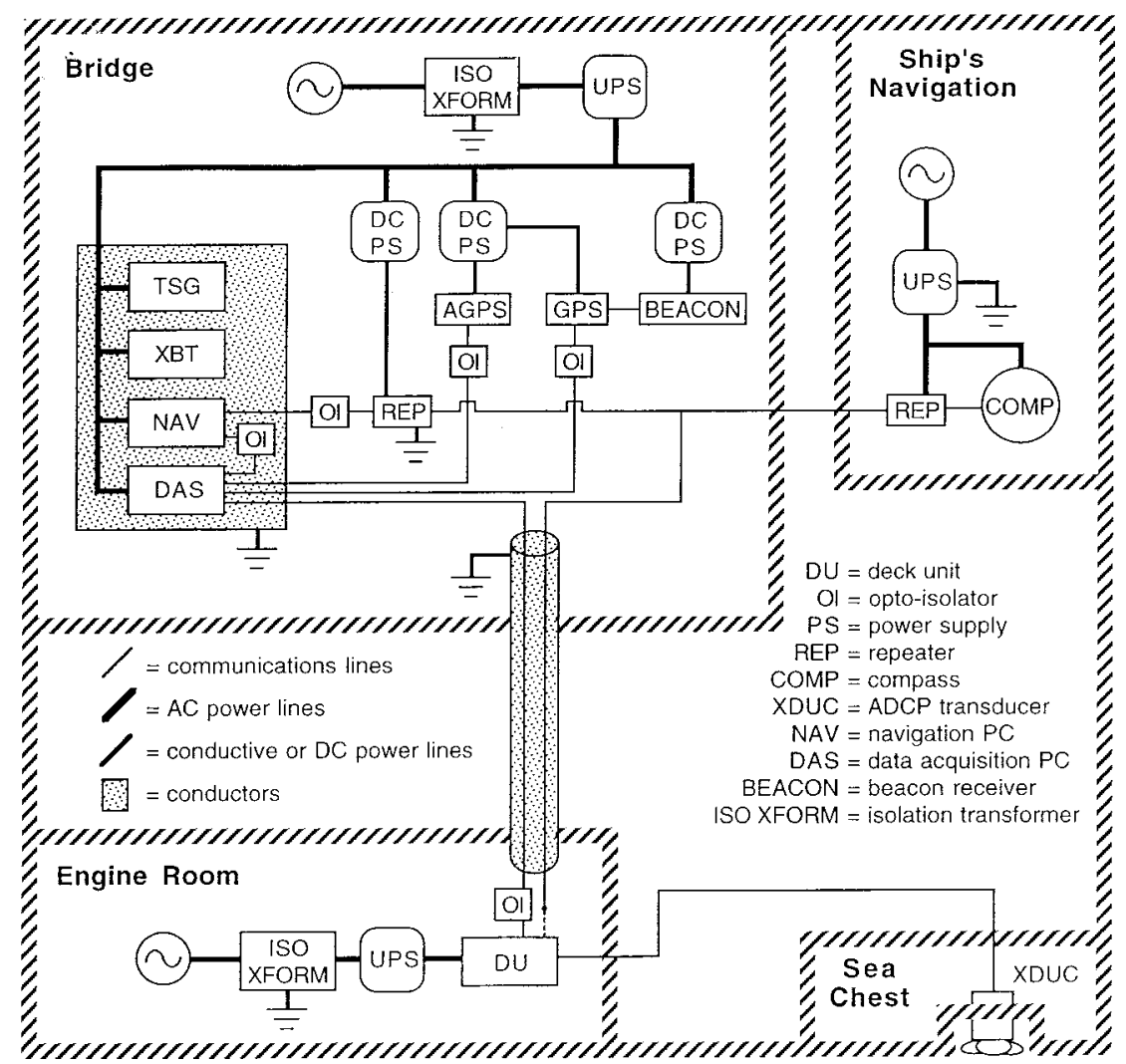

FIG. 3. Block diagram of the electrical interfacing among the ADCP transducer, deck unit (DU), DAS, and NAV computers, gyrocompass, and GPS receivers. 
PCs. A switch is employed to switch a single monitor and keyboard among each of the four computers. The ADCP system utilizes two computers: the Data Acquisition System (DAS) computer and the navigation (NAV) computer, which processes the compass heading data sent to the DAS. The other two computers are used by NOAA (Benway et al. 1993) as part of their volunteer weather observation, XBT, and thermosalinograph systems.

In addition to the computers, the system in the radio room comprises a global positioning system (GPS) receiver, an attitudinal GPS (AGPS) to provide gyrocompass error correction, and a beacon receiver to obtain differential GPS (DGPS) position error information. The AGPS establishes an accurate heading reference so that gyro errors can be reduced later in postprocessing. The DGPS removes selective availability (SA) dithering and transmission errors from the GPS signal while the ship is within range of one or more coastal radio direction finding (RDF) beacon transmitters. At present, this differential correction extends out to about $575 \mathrm{~km}$ from New Jersey and about $285 \mathrm{~km}$ from Bermuda.

Power for the bridge and engine room equipment is provided from separate isolation transformers and fully isolated uninterruptable power supplies (UPSs). Optically isolated serial port adapters are employed wherever possible. The ship is equipped with an Anshutz gyrocompass with 360:1 synchro output so that for every degree change in heading the gyrocompass analog output traverses its entire range. This format provides improved compass precision but results in a system that resets to a north heading after a power outage. The occurrence of heading resets proved to be one of the more difficult problems to overcome and has only been satisfactorily addressed by rerouting the gyro synchro signal from the deck unit to the DAS PC. The synchro output is fed to the Anshutz compass repeater that converts stepper data into a continuous serial data stream that is supplied to the DAS PC through the NAV PC.

The deck unit receives its operating parameters from the DAS each time the DAS is restarted. These set the ensemble interval, bin size, pulse length, and scaling parameters. The deck unit communicates with the DAS computer on the bridge via a multiconductor serial cable consisting of twisted pair wires operating at 19.2 kbaud. This cable follows a convoluted path across the engine room, up the port stack, behind various panels, and up another conduit to the bridge. The deck unit communicates with the ADCP transducer through a 70-m multiconductor shielded cable that runs along a cable rack on the starboard side of the vessel and enters the cofferdam through a conduit and watertight gland.

The arrangement for the underwater unit onboard the CMV Oleander follows RD Instruments' guidelines (RD Instruments 1991) for installation on research vessels and differs only in the details. Figure 4 schematically shows the cofferdam and sea chest arrangement. Access to the $2 \mathrm{~m} \times 3 \mathrm{~m} \times 1.5 \mathrm{~m}$ high cofferdam is

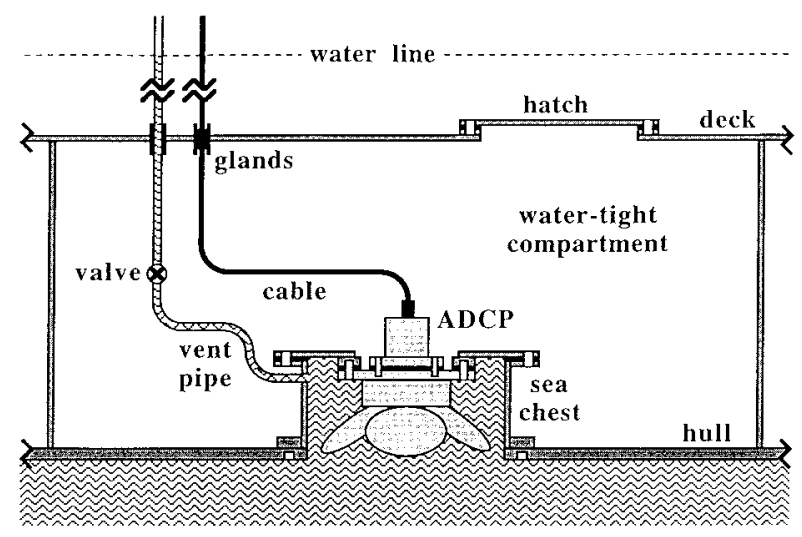

FIG. 4. Schematic view of the cofferdam (watertight compartment) containing the ADCP transducer and sea chest. Access is gained through a manhole (hatch) located all the way forward in hold 3. The cable from the transducer is fed through a conduit (gland), up two deck levels, and back to the deck unit in the engine room. The sea chest is located in the center of the cofferdam, and the vent pipe allows the escape of trapped air. The sea chest can be opened and closed from the top and bottom via gasketed metal plates, as described in the text.

gained through a hatch through the inner bottom. Three conduits lead down to the cofferdam. Two are for electrical connections. The third is a vent pipe through which trapped air in the sea chest can vent to the atmosphere. The sea chest is welded to the hull and the vent pipe is welded to the side of the sea chest. The sea chest can be sealed on the top from the inside and on the bottom from the outside of the ship by divers. In operation, the ADCP is bolted to and seals the sea chest on the inside. To remove the transducer, divers first attach a gasketed bottom cover plate from the outside. With the exterior cover plate installed, the transducer can be unbolted and replaced with a steel plate, after which the outside cover plate can be removed. The whole operation takes a few hours, most of which is consumed by the diving operations.

The sea chest, Fig. 4, is designed for a standard RD Instruments $150-\mathrm{kHz}$ narrowband transducer and is certified by Lloyds of London for use on the CMV Oleander. (Certification by an insurance carrier will be required of any installation that could affect the ship's hull integrity.) The walls of the sea chest have been painted with marine antifouling paint over sigma-coated tar epoxy to prevent corrosion. Even though the transducer was not painted, as per the recommendation of RD Instruments, marine growth and bio-fouling have not been a major problem. The outer edges of the transducer surfaces are recessed above the hull line by 2.5 $\mathrm{cm}$ so as not to obstruct the flow of water along the hull. The mechanical aspects of the sea chest and transducer have been very successful. Since operation started in the fall of 1992, we have not experienced excessive corrosion, bio-fouling, or failure of the transducer.

One of the primary goals in the project was to obtain 
ADCP transects every time the ship made a run between New Jersey and Bermuda, not just at those intervals when a NOAA observer went along to make XBT observations. However, during discussions with the ship's owners and captains, we were clearly warned that while they welcomed the project, they could not provide the personnel to monitor the equipment. Thus, an important feature of the system was that it had to be able to run autonomously for at least the weeklong round-trip to Bermuda and hopefully for several weeks to minimize travel to and from the ship. There were two primary requirements that such an autonomous system had to meet. First, it had to be able to recover from inadvertent interruptions caused by power failures, software faults, or unintentional keyboard entries. Second, it had to be able to change the configuration of the ADCP's data acquisition since the ship was going to transit from shallow to deep water and back again. We also wanted the system to be able to back up completed data files to a separate disk and to keep $\log$ files of any changes or errors in the system. A last consideration was that we wanted to use the same methodology for collecting the data as in RD Instruments DAS 2.48 software because it had been well tested by the community and was "thoroughly" understood.

Our options in this regard were either to write a specialized version of RD Instruments' data acquisition system with various autonomous features or to modify the existing program. J. Lewkowitz, then at RD Instruments, proposed that he could meet our needs through the use of "user exit" programs within the current DAS framework. This he did through a set of routines that make up what is collectively called the AutoADCP software package. In sequence, this is how the system works. After boot-up, the DAS PC's AUTOEXEC.BAT file calls a batch file named FLAGEXEC.BAT, which defines the backup directory, turns on the ability to read heading data from the NAV PC, starts a software watchdog timer, and finally starts the DAS 2.48 acquisition program. Within the DAS there is a user exit program, HEAD.EXE, which reads the heading data provided by the NAV PC from the serial port after each ping and puts it in the data stream. Another user exit program, FLAG.EXE, compares the ship's position at the end of each ensemble against the set of predefined polygonal regions, shown in Fig. 5, to see if the ship has passed from one region to another. If not, the data acquisition continues. However, if there has been a region change, FLAG.EXE then copies a predefined configuration file that applies to the new region into the DAS's default configuration file and reboots the PC. Upon rebooting, the ADCP automatically starts pinging, using the configuration appropriate for the new region. Thus, such things as pulse length, bin size, and the use of bottom tracking, etc., can easily be altered as required. The AutoADCP continues to operate in port although it is usually configured not to record any data and to do minimal pinging. Once the ship leaves the port region, a new configuration that turns on the usual ADCP func-

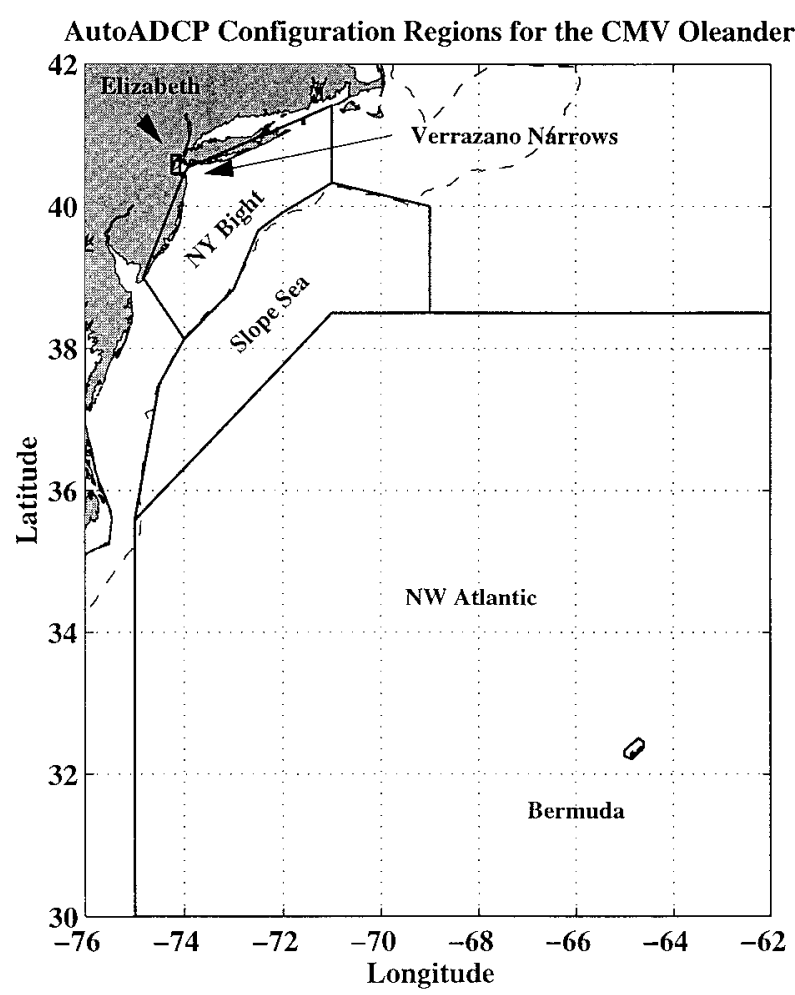

FIG. 5. AutoADCP configuration regions for the CMV Oleander along its route from New Jersey to Bermuda. The dashed line represents the 100-m isobath.

tions is set into operation. FLAG.EXE also resets the watchdog timer at the end of each ensemble, annotates configuration changes in a log file, and copies a completed ping data file to a backup disk.

Another modification to the DAS 2.48 that we have incorporated into the system is the UE4.EXE routine generated by Dr. E. Firing at the University of Hawaii. This is another user exit program that, in this case, replaces RD Instruments' NAVSOFT.EXE and provides the user the choice of any of four communications ports on the DAS PC for navigation data. UE4's primary function is to improve navigation by recording the ship's GPS position precisely at the end of the ensembles thus allowing for more precise computation of the ship's velocity. A secondary function that has become relatively more important is the processing and recording of heading data from the attitudinal GPS unit. These data are used during post cruise processing to reduce gyro heading errors.

To collect acoustic backscatter intensity data for possible use in generating a climatology of zooplankton abundance along the section using the CMV Oleander's ADCP, we included the AGCAVE.EXE user exit program in the configuration. This routine calculates and stores the ensemble averaged backscatter intensity profiles from each of the ADCP's four transducers. 

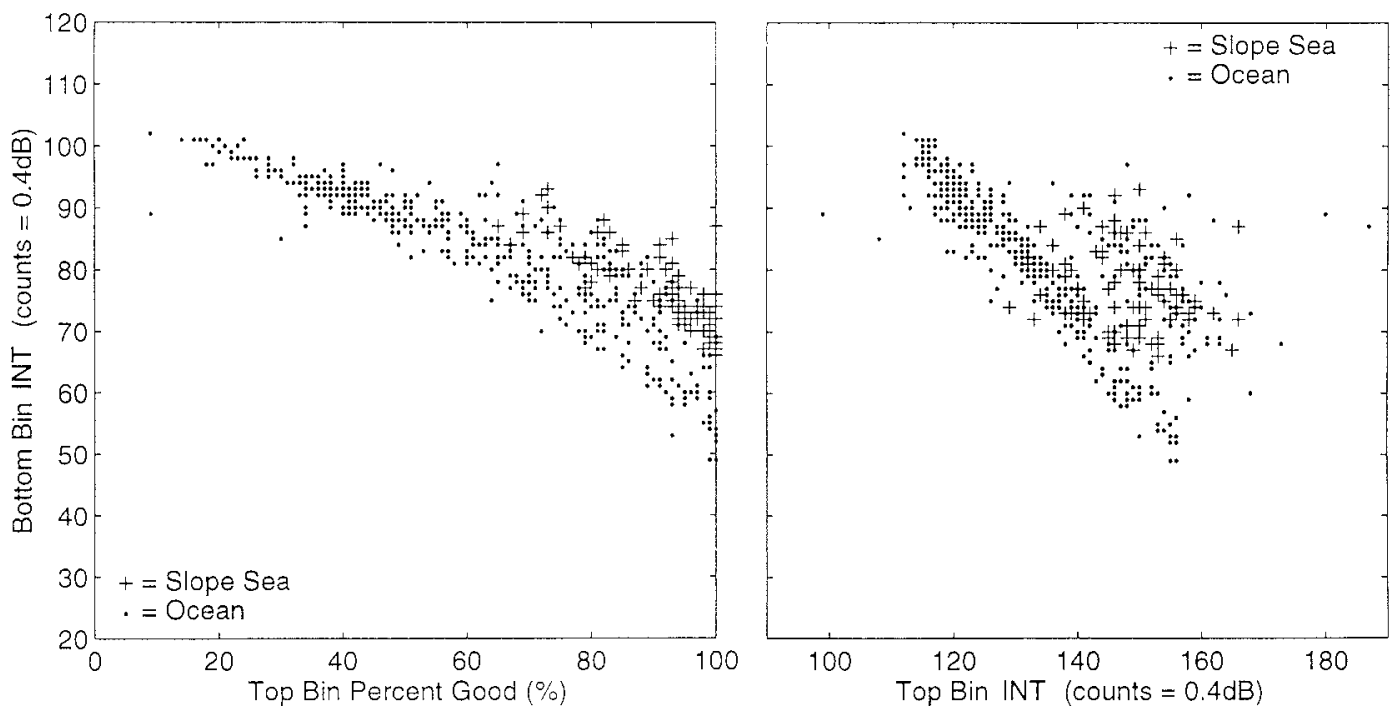

FIG. 6. Bottom bin return signal intensity vs top bin percent good (left panel) and top bin return signal intensity (right panel) during the 28-30 November 1992 outbound cruise. The bottom bin contains little if any return signal and thus is indicative of the background noise level. The "ocean" points are from the Gulf Stream southeast to Bermuda. The "slope sea" points are from the stream northwest to the shelfbreak and show higher intensities due to higher plankton concentrations there.

\section{Performance and improvement}

The performance of the ADCP system depends upon 1) the penetration of the acoustic pulse into the water column, which is related to length of the transmitted pulse and the attenuation of the water; 2) the attenuation of acoustic pulses by bubbles; 3 ) the concentration of acoustic scatterers in the water column; and 4) the ambient noise level dominated by backscattered energy from the ship and the bubble cloud that may be underneath it.

The presence of bubbles is the most troublesome since they attenuate and scatter both the transmitted and returned signals. The source of bubbles is sweep-down of surface waters in front of the vessel. This becomes a major problem in heavy seas when the pitching and rolling motions of the vessel cause extensive foaming around the bow prior to subduction. On the CMV Oleander, this is particularly serious during the ship's return transit from Bermuda to New Jersey when the ship is lightly loaded and the bow rides about $0.6 \mathrm{~m}$ higher.

Two helpful measures of signal quality in the ADCP are the percent good and backscattered intensity from the deepest bin. The first is defined as the percent of all pings in a bin per ensemble that meet the ADCP's signalto-noise criterion. The second uses the acoustic intensity in the deepest bin as a measure of total system and ambient noise because in deep water this bin usually has little backscattered energy from the ADCP. Note that acoustic energy is often not from that bin-it is simply a measure of noise from below the ship. Early in the project it became evident that data from outbound trips were superior to those from inbound trips, and attenuation from bubbles and noise were suspected as being the major cause of the reduced data quality. Examination of several years' noise data shows that under poor conditions a relationship exists between the percent good and noise. An example of this can be seen in Fig. 6 for an outbound cruise in fall 1992. The left panel shows bottom bin intensity against percent good in the top bin, and the right panel shows bottom bin intensity against the corresponding signal level in the top bin. When the intensity level dips below about 100, the percent good increases rapidly. At the same time, the corresponding return intensity levels increase substantially in the near surface bins. In extreme situations with very low percent good, the intensity profile is nearly uniform throughout the profile. This indicates that the reduction in performance is due to the presence of bubbles rather than to electrical or ship noise per se because the bubbles will attenuate both the outgoing signal (cf. New 1992) and its return. It is assumed bubble oscillations are the primary source of the noise itself.

Just a slight reduction in speed such that bubbles are not swept underneath the vessel (for a given sea state and cargo load) can lead to a dramatic improvement in performance. Figure 7 shows ship's speed, intensity, and percent good at 28-, 100-, and 404-m depths as a function of time during a northbound cruise. At day 250.5 when the ship reduced its speed only about $2 \mathrm{kt}$, there was an abrupt drop in intensity in the bottom bin and an increase in the upper bin, and corresponding improvements in percent good. This is almost certainly due to a sharp reduction in the presence of bubbles underneath the sea chest. Their absence allows for a 

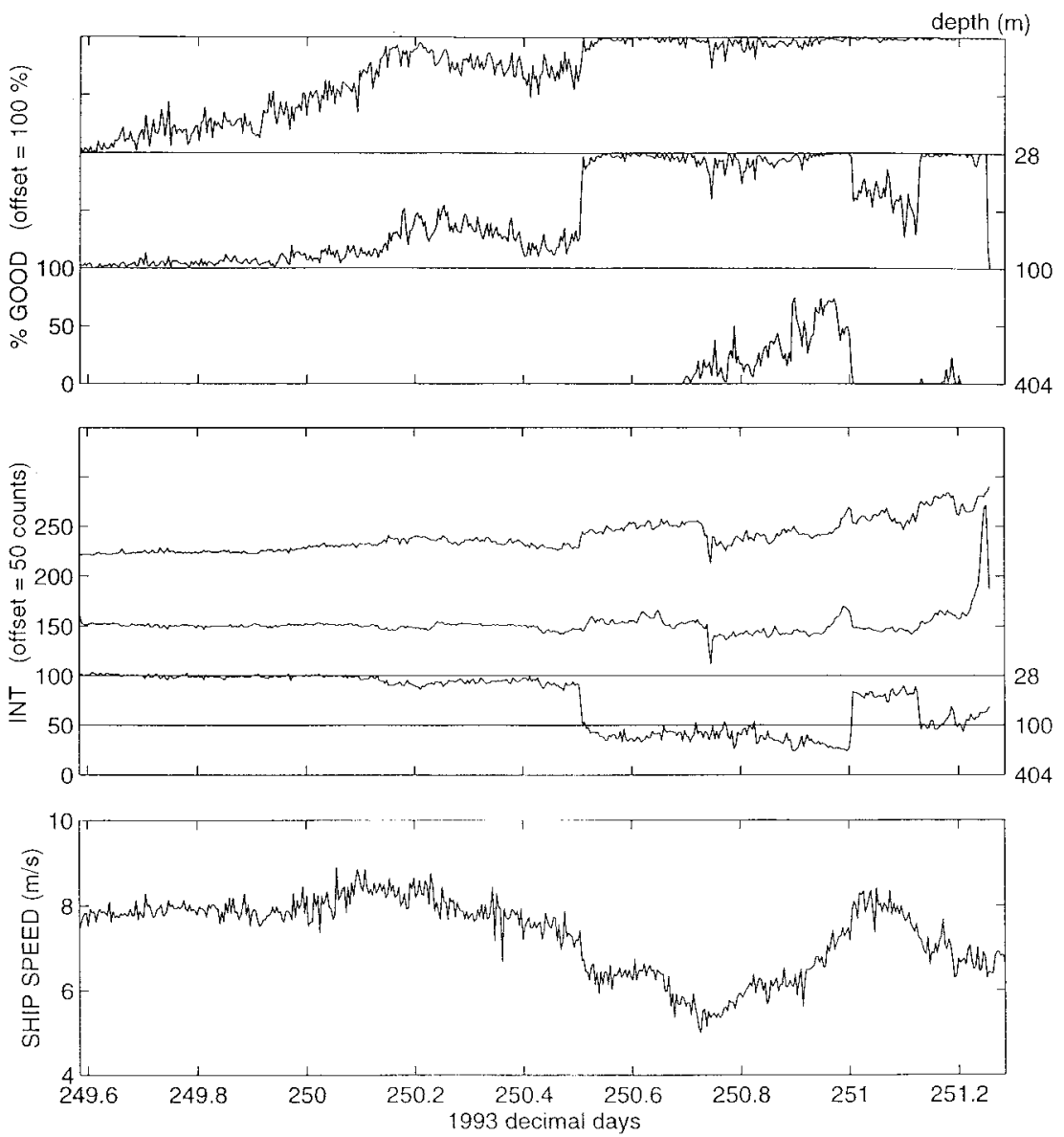

FIG. 7. Percent good (top panel), return signal intensity (middle), and ship speed (bottom) vs time for the 7-9 October 1993 inbound cruise. The percent good and intensity are shown as offset curves for the bins centered at 404, 100, and $28 \mathrm{~m}$. The vertical axis applies to the bottommost curve, and the other curves are successively offset upward by the indicated amount.

stronger signal out and back, hence the increase in intensity in the upper bin, a slight increase in the middle bin, and a sharp drop near the bottom of the profile. But the bottom bin is too far away for any return signal to be detected-confirmed by the lack of increase in percent good-so it actually represents a drop in ambient noise under the vessel. Note the sharp increase in bottom bin intensity at day 251.0 when the ship's speed was increased approximately $1 \mathrm{kt}$. Since the bottom of the hull is perfectly flat and rather unlike research ships, bubbles probably blanket the whole underside of the vessel once bubble sweep-down starts.

Strong evidence for the presence of bubbles underneath the ship in heavy seas also was found by measuring the rate of pressure increase in the sea chest vent pipe while it was sealed at the top. This was done several times in varying weather conditions. In good weather the vent pipe showed no increased pressure when capped, whereas in poor weather the pressure buildup was very rapid (minutes).

The amount of successfully returned ADCP data has steadily increased since the beginning of the measurements in August 1992 as multiple problems were overcome. In particular, the system reliability and number of cruises available increased greatly after October 1995 due to the installation of UE4.EXE (mentioned previously) and the upgrading and reconfiguration of the electrical system (to be discussed). During the period from October 1992 through January 1997, omitting missing cruises due to system upgrades, instrument failures, drydocking, holidays, totally bad weather, and those cruises that will be recovered later, there remain 141 outbound and 126 inbound cruises. Considering just the velocity data at $50 \mathrm{~m}$, the number of cruises with gaps of less than $60 \mathrm{~km}$ anywhere along the track is 83 outbound and 32 inbound, while the number of cruises with gaps of less than $20 \mathrm{~km}$ in the Gulf Stream is 99 outbound and 53 inbound. The mean percentage of profiles containing any good data is $89 \%$ outbound and $70 \%$ inbound. Of those profiles, the mean percentage containing good velocity data at 50-, $100-, 150-, 250-$, and 350-m depths are 96\%, 91\%, 75\%, 
TABLE 1. Summary of bottom-track results. Angle is the misalignment angle (degrees), diff is the difference between outbound and inbound angle values, scale is the speed scale factor, $N$ is the number of samples comprising each mean, and each sample is a 30-40-min average. 1993 and 1994 are bottom track only, and thus the misalignment angle is between the gyrocompass and the ADCP transducer. For 1995 angle represents the angular offset between the AGPS and transducer.

\begin{tabular}{|c|c|c|c|c|c|c|c|c|c|c|}
\hline \multirow[b]{3}{*}{ Year } & \multirow[b]{3}{*}{$N$} & \multicolumn{4}{|c|}{ Outbound } & \multicolumn{4}{|c|}{ Inbound } & \multirow[b]{3}{*}{ Diff } \\
\hline & & \multicolumn{2}{|c|}{ Angle } & \multicolumn{2}{|c|}{ Scale } & \multicolumn{2}{|c|}{ Angle } & \multicolumn{2}{|c|}{ Scale } & \\
\hline & & Mean & Std & Mean & Std & Mean & Std & Mean & Std & \\
\hline 1993 & 14 & -1.43 & 0.14 & 1.011 & 0.003 & 0.56 & 0.16 & 1.020 & 0.018 & 1.99 \\
\hline 1994 & 12 & -0.31 & 0.41 & 1.014 & 0.007 & 1.75 & 0.29 & 1.015 & 0.010 & 2.06 \\
\hline 1995 & 12 & 1.89 & 0.06 & 1.012 & 0.003 & 1.89 & 0.07 & 1.015 & 0.003 & 0 \\
\hline
\end{tabular}

$44 \%$, and $9 \%$, respectively, for outbound, and $92 \%, 70 \%$, $38 \%, 13 \%$, and $4 \%$, respectively, for inbound.

\section{Navigation \\ a. Gyrocompass}

Determination of geographic-referenced velocities requires knowing the ADCP transducer's orientation relative to the ship's compass and the ship's motion while acquiring the ship-referenced velocity profiles. The accuracy of geographic-referenced velocity depends crucially upon the calibration and stability of the gyrocompass and GPS navigation systems used to track the ship.

The importance of the gyrocompass accuracy and repeatability to the ultimate accuracy of the ADCP velocity profiles is very easy to appreciate. At a typical vessel speed of $8 \mathrm{~m} \mathrm{~s}^{-1}$, a heading error of $1^{\circ}(=1 / 57$ radians) will lead to an apparent cross-track velocity of $8 / 57=0.14 \mathrm{~m} \mathrm{~s}^{-1}$ ! This would be unacceptably large; fortunately, this happens only very rarely and can usually be detected, as will be pointed out below. The heading given by the gyrocompass depends in complex and subtle ways not merely upon the heading of the ship but also on its latitude, speed, and heading as well as recent changes in speed and heading (Griffiths 1994). These reflect the fact that the gyrocompass is sensitive to accelerations and will execute a damped oscillation with a period of $84 \mathrm{~min}$, the so-called Schuler oscillation (Pollard and Reed 1989). Because the Oleander's course is a straight line between New Jersey and Bermuda, the most significant errors in gyrocompass data occur during periods of heavy rolling (see below).

\section{b. Bottom tracking}

Gyrocompass heading error can be reduced whenever an outside reference heading is available. The traditional method of obtaining a reference heading for the ADCP is to use the bottom track mode (see Pollard and Read 1989). In this mode the ship's velocity over the bottom is obtained from the Doppler shift of the bottom-reflected echoes. Comparing this with ship velocity estimated from first differencing successive GPS position fixes yields a speed error or scale factor and a heading offset or misalignment angle between the gyrocompass and ADCP transducer. These are estimated routinely for each transit across the shelf. The results are summarized in Table 1 for 1993 and 1994.

The $1.1^{\circ}$ difference in mean angle between 1993 and 1994 is because the ADCP was removed for service during dry-docking. The angle and scale values in Table 1 are shown separately for the out- and inbound transits for 1993 and 1994 to highlight the $2^{\circ}$ difference in gyrocompass heading error (last column). This heading dependence of the gyrocompass error agrees quite well with that of King and Cooper (1994).

The bottom-tracking analysis was made difficult by a problem we referred to as "shelf contamination," which was resolved in January 1997. This problem occurred only over the shelf when the bottom was within range of the ADCP and caused speed biases in the direction of travel of up to $1 \mathrm{~m} \mathrm{~s}^{-1}$. Instances of this contamination also appeared to be related to sea state. Analysis to date suggests that the problem was due to the inclusion of depth bins contaminated by the bottom return in the DAS reference layer calculation. Reflected energy within the ADCP's nearly vertical acoustic sidelobes would bias the Doppler shift low, thereby introducing a bias in the recorded water velocities in the direction of travel. The difficulty with this theory is that the problem sometimes occurred when the reference layer was well above the bottom. The problem was unexpected since to our knowledge it had not been a factor on research vessels operating in shallow waters, so it may be related to the CMV Oleander's hull form, which is much longer, wider, and flatter. The approach we have taken simply was to turn off the reference layer calculation in the shallow water regions and this has eliminated or at least vastly reduced the problem. The effect of the problem on bottom track calibrations was avoided by disgarding runs where the scale factor deviated by more than a few percent from 1.0.

\section{c. Attitudinal GPS}

The second approach to providing a stable reference heading is through use of an AGPS, which we have been operating since June 1995. The AGPS (an Ashtech 3DF) uses differential carrier phase measurements from four antennas to determine ship's heading, roll, and pitch 

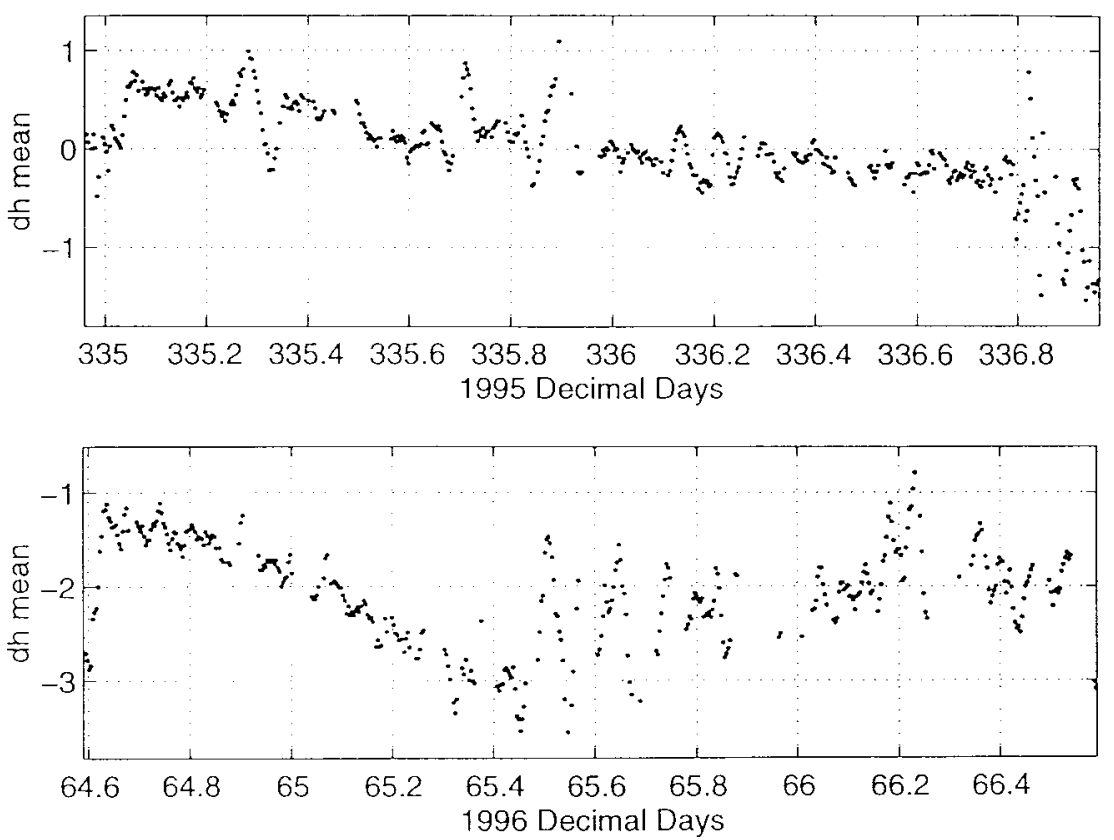

FIG. 8. Heading difference (dh) vs time for the 1-3 December 1995 outbound cruise (top panel) and the 5-7 March 1996 inbound cruise (bottom); dh is the difference between the headings measured by the gyrocompass and the AGPS, and thus is an indicator of gyrocompass error.

as a function of time. With an antenna separation of a few meters the heading resolution is less than $0.1^{\circ}$, and the roll and pitch are twice that (Ashtech 1994). The angular offsets of the ADCP relative to the Ashtech antennas are also summarized in Table 1 for 1995 . The larger standard deviations in 1993 and 1994 than in 1995 are due to the errors in the gyrocompass heading compared to that of the AGPS. While the AGPS significantly reduces the geographic-referenced velocity errors, it

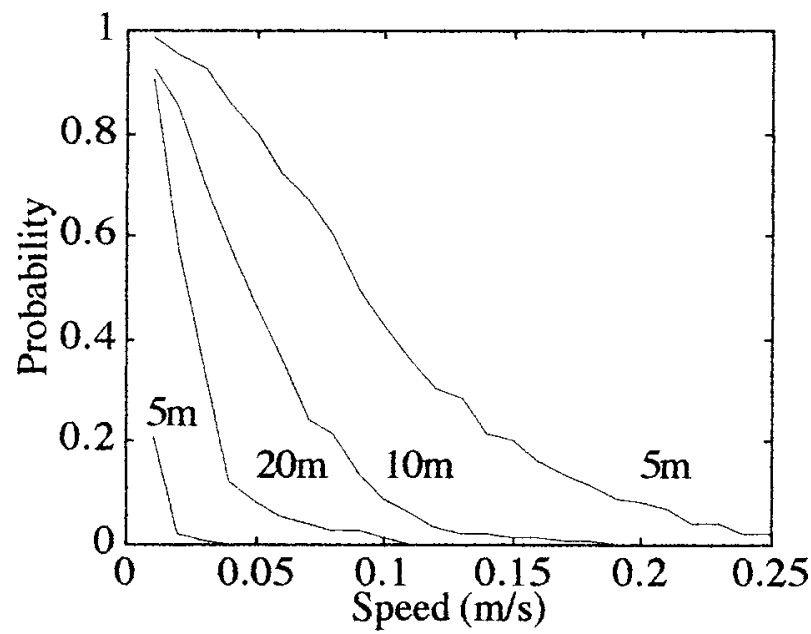

FIG. 9. Probability of GPS dithering (civilian degradation) resulting in an apparent speed greater than a certain value as a function of time interval in minutes. The short curve to the lower left is for beacon-corrected (differential) GPS cannot replace the gyrocompass because of data lapses primarily due to shadowing of the satellites by the ship's mast. The heading data are used to correct the gyro error when processing the velocity data; the roll and pitch data have been useful in determining the ship's response to sea state and thus the likelihood of bubbles under the hull. Figure 8 shows a typical plot of the heading difference between the AGPS and gyrocompass. The AGPS heading is available more than $70 \%$ of the time. Fortunately, much of the gyro error varies slowly in time such that it can be estimated by interpolation or curve fitting. In 1995 the misalignment angle in Table 1 is calculated between the AGPS antenna array and the $\mathrm{ADCP}$ transducer, and the difference between outbound and inbound is zero.

\section{d. Differential GPS}

Since determination of geographic-referenced velocities requires knowing the actual speed over the bottom, any errors in GPS position will reduce the accuracy of the calculated velocities. As is well known, the accuracy of the SA GPS code is degraded by introduction of a slight "dithering" by the military (Magnavox 1991). The stated accuracy under these conditions is that the computed position is within $100 \mathrm{~m}$ of the correct position $95 \%$ of the time. This has a significant short-term effect on ADCP velocity estimates, which can be seen by computing the apparent speed of the ship due simply to the dithering of position. Figure 9 shows the probability (based on a 5-min sampling rate for $24 \mathrm{~h}$ in 


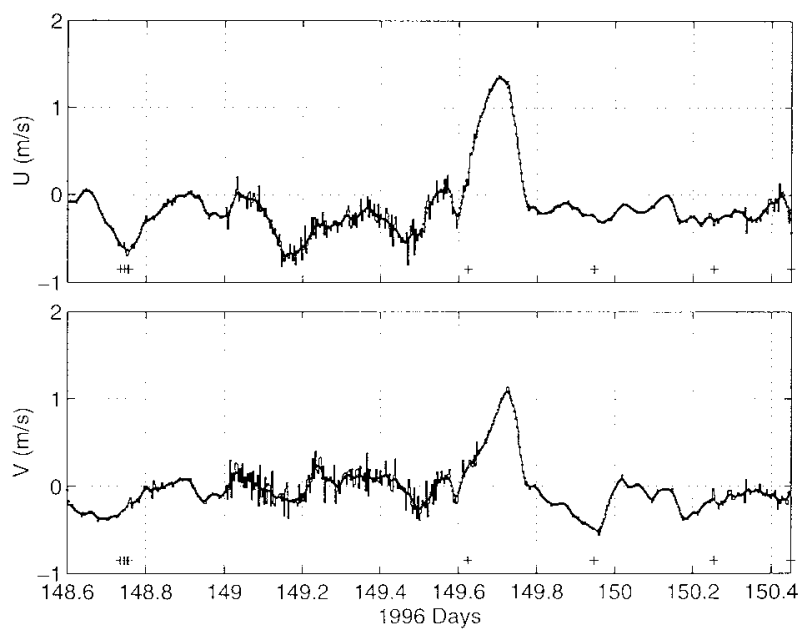

FIG. 10. Velocity components (geographic $U$ and $V$ ) averaged between 40- and 128-m depth vs time (decimal days) for the 28-30 May 1996 inbound cruise, showing the difference between velocities computed from GPS data with (smooth portions) and without (spiky portions) the differential correction. Typically, the DGPS beacon signal is receivable out to $575 \mathrm{~km}$ from New Jersey (just past the Gulf Stream) and $285 \mathrm{~km}$ from Bermuda.

Hamilton, Bermuda) of apparent speed exceeding a given value for three different time intervals. The probability of apparent speed exceeding $0.1 \mathrm{~m} \mathrm{~s}^{-1}$ is less than 0.4 and 0.08 , for GPS positions 5 and 10 min apart, respectively. The general conclusion is that dithering introduces significant velocity errors for individual ensembles, but its effect is lessened for averages spanning 20 min or more. For 20-min intervals the probability of an error greater than $0.05 \mathrm{~m} \mathrm{~s}^{-1}$ is approximately 0.08 . The main impact of the dithered signal is to decrease the spatial resolution of the ADCP data.

However, the dithering can be eliminated by using DGPS corrections from shore-based reference stations transmitting from RDF beacons. This network of beacon transmitters, with a range of $350-650 \mathrm{~km}$, is maintained by the U.S. Coast Guard and the government of Bermuda. We upgraded our GPS (a Leica MX-4200) to accept differential corrections beginning in June 1995. Since the CMV Oleander operates within range of several RDF beacons, we chose a beacon receiver (Northstar 8401) able to monitor and automatically select the strongest of several beacon signals. Figure 10 illustrates the contrast in velocity noise when receiving and not receiving the corrections. Out to approximately $575 \mathrm{~km}$ from New Jersey (just past the Gulf Stream) and within approximately $285 \mathrm{~km}$ of Bermuda the velocity is very smooth. In between, where no DGPS is available, the 5 -min ensemble velocity data show a variability on the order of $\pm 0.15 \mathrm{~m} \mathrm{~s}^{-1}$ due to the dithering. It is also evident from the figure that the fluctuations have limited impact once the data have been smoothed.

\section{Electrical noise}

The biggest problem with the ADCP installation on the CMV Oleander has been diagnosing and containing electrical interference from the ship's power grid. Despite a careful initial effort to lay out the system's electrical components in a traditional star pattern to minimize ground loops, it became clear almost immediately that the ADCP system's performance was very sensitive to electrical noise and power disturbances. These propagate easily into and cause a range of difficulties in the ADCP system such as unintentional and unexplained rebooting of the DAS PC to more serious problems such as a catastrophic failure of the deck unit, DAS computer, or GPS. As is typical of commercial ships, the ship's electrical power is derived from an $800-\mathrm{kW}$ shaft generator at sea or one of three auxiliary 410-kW Caterpillar $\mathrm{V}-12$ diesel electrical generators when in port. The shaft generator runs directly off the propeller shaft. The line voltage is specified to be $110 \mathrm{VAC}$ but observations show it closer to 104 VAC under normal conditions. The origin of some transients have been traced to starting and stopping the bow thruster and to the hydraulic pump motor that operates the ship's stern ramp.

In the early days of the program, the ADCP PCs and the deck unit would often reset due to the large power transients when the ship switched from the auxiliary to the shaft generator and back again. Line transients become more common in heavy weather when the propeller breaches the surface, causing shaft rpm fluctuations. Resets occurring during heavy weather have been established from the ship's weather log and more recently from the AGPS roll and pitch data. Power fluctuations occur frequently at these times and can be so acute that in the most severe weather the crew sometimes switch over to the auxiliary generator. However, even when operating from the auxiliary generator, transients have been a problem.

To reduce and if possible eliminate susceptibility to the power line transients, separate uninterruptable power supplies were installed for the computers and deck unit. Initially, we installed American Power Conversion standby UPSs. These UPSs are inexpensive and work very effectively in the office but caused ground faults to occur within the ship's power distribution system. Merchant ships use a power distribution scheme in which both line and neutral are isolated from ground. If either side of the line develops continuity to the hull of the ship, a ground fault condition will be indicated on the ship's electrical equipment. Thus, these UPSs were replaced by on-line UPSs (Clary Corporation) and Topaz isolation transformers. Also, an optical isolator was added on the serial line between the DAS PC and the deck unit to further reduce possible noise. These helped but did not entirely remove the problem.

A more serious difficulty came from electrical transients that reset the deck unit, initiating a new header in the ping data file, zeroing the heading, and thereby 


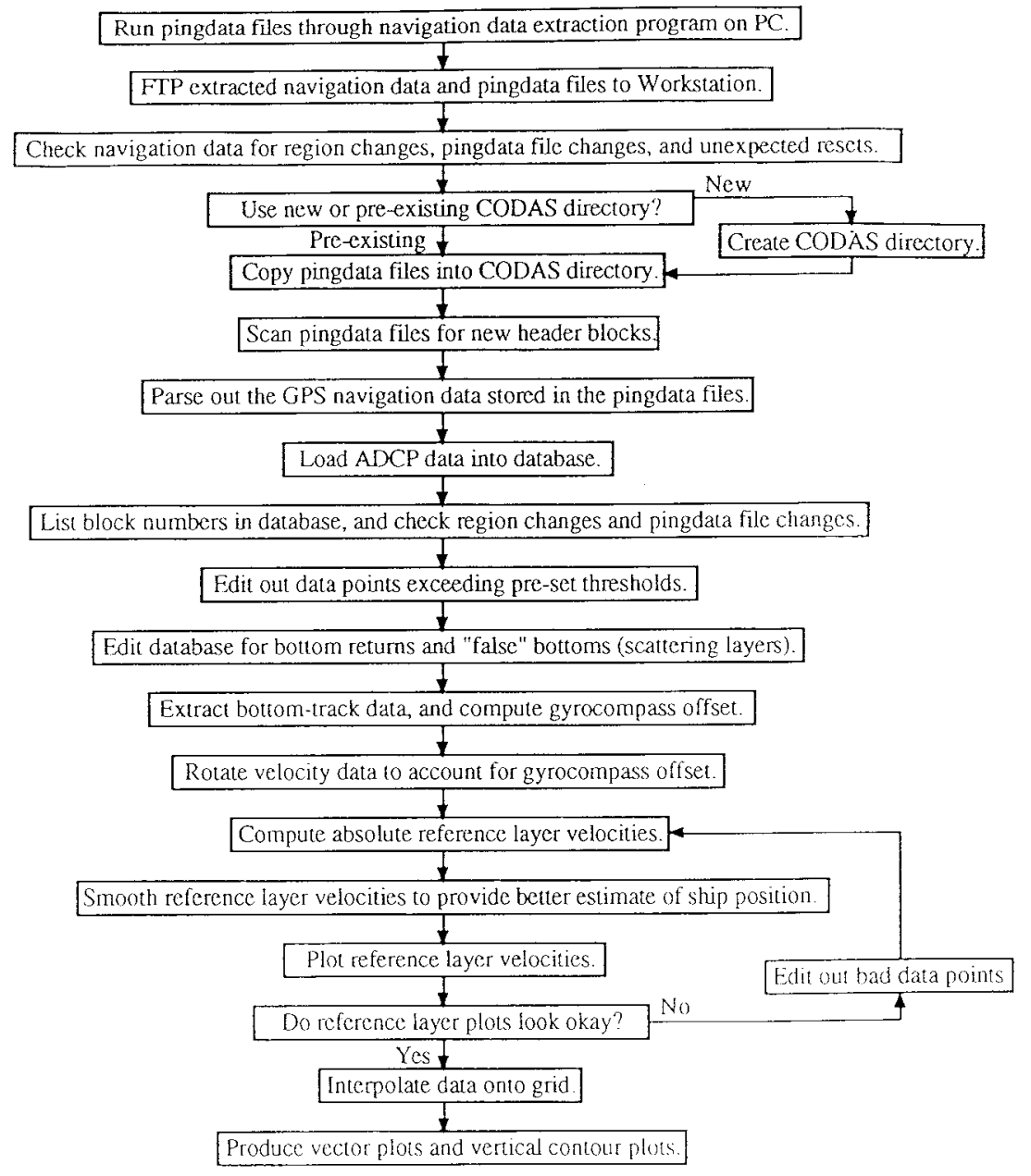

FIG. 11. Flow diagram of the ADCP data processing.

losing the absolute heading. Rerouting the gyro synchro signal from the deck unit to the DAS PC through the NAV PC eliminated the occurrence of these resets (April 1993). The absolute heading after one of these resets was almost completely recoverable by just taking the difference in headings before and after the reset and rotating the data by this offset during postprocessing. This correction was possible because the ship steams on a nearly constant heading for most of its journey. Although some loss of accuracy could not be avoided, we believe that the corrections are good to $\pm 0.3^{\circ}$.

Even after very carefully reviewing and testing for ground loops and eliminating one possibility after another, system resets (but not heading resets) continued to occur. In the calmer seas of summer they occurred rather infrequently, but in winter they continued to be a nuisance. Suddenly, after $2 \frac{1}{2}$ years of operation, the deck unit failed catastrophically, and the cause of the failure shed some light on the remaining reset problems. A failure occurred in circuit boards within the deck unit that are connected directly to the shielded 70-m-long transducer cable running from the engine room to the ADCP transducer. This cable lies in a tray and right next to the ship's power distribution cables for refrigerated containers and windlasses. Suspecting that it was possible to induce enough voltage into the ADCP cable to disrupt the electronics connected to that cable, we moved the transducer cable away from the others in the tray, drastically reducing the number of resets.

\section{Processing and results}

Visits to the ship for routine inspection and data retrieval typically occur once or twice per month. The routine inspection includes preliminary examination of the data files on the ship to make sure all systems are functioning normally. The ping data files are collected on removable SyQuest disks and transferred to a Sun workstation at URI where they are inspected to verify the data quality. The raw ping data files are processed using the CODAS software system developed by the ADCP group at the University of Hawaii (Firing et al. 


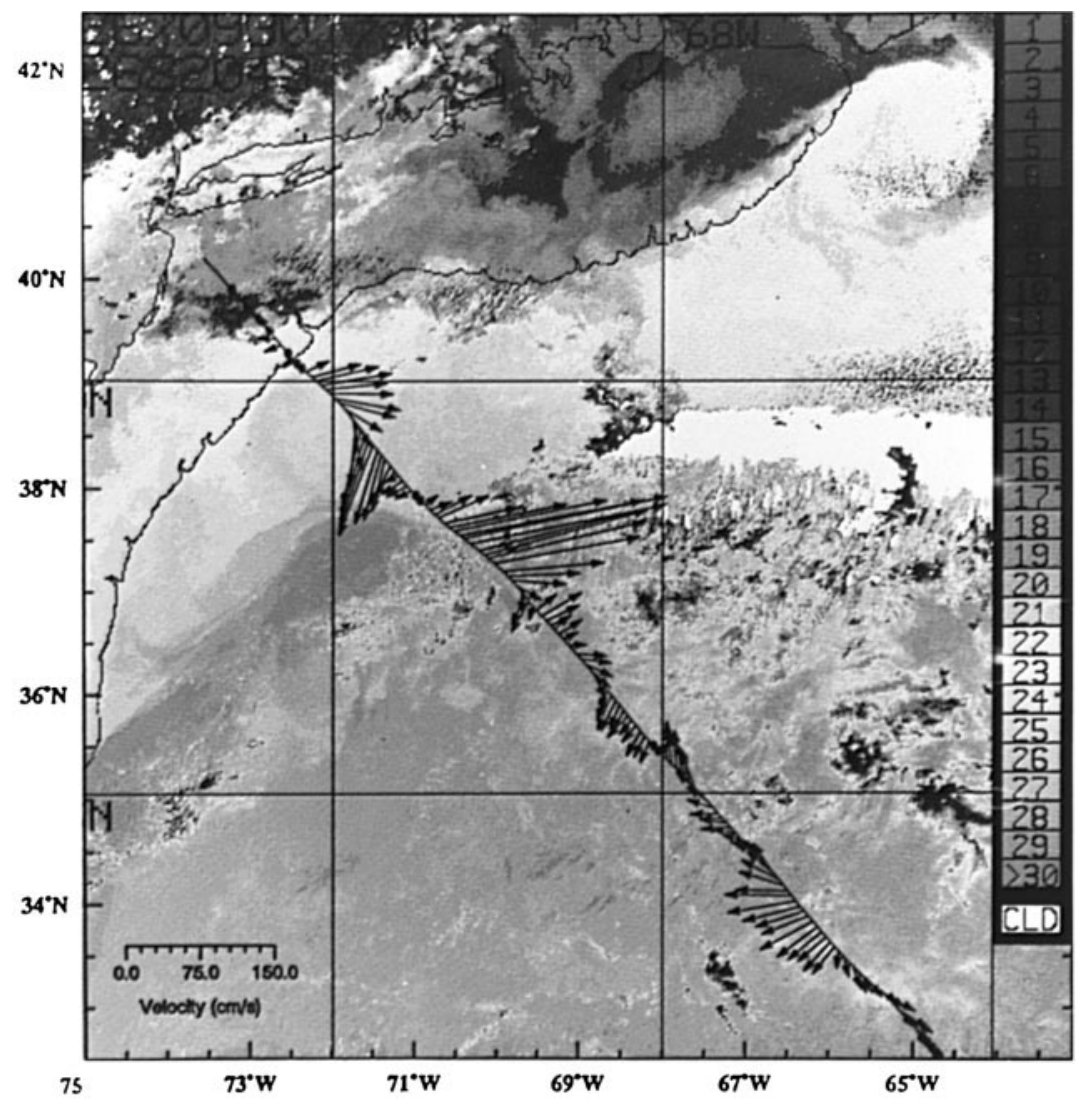

FIG. 12. Stick plot of $15-\mathrm{min}(6 \mathrm{~km})$ averaged ADCP velocities at the 52-m depth level from the 24-26 September 1993 outbound cruise superimposed on NOAA/AVHRR sea surface temperature (SST) composited images from 25-26 September. Velocities less than the instrument threshold (about $1 \mathrm{~cm} \mathrm{~s}^{-1}$ ) are indicated with a dot. SST $\left({ }^{\circ} \mathrm{C}\right)$ is indicated in the grayscale, and the 200-m isobath is indicated by the solid line.

1995). A flow diagram of the data processing procedure is shown in Fig. 11. For a normal cruise (2 days of data) it takes a trained processor about 4 hours to complete the entire processing procedure. The nonediting steps are fairly routine, while the editing steps require processor intervention. Difficulties and delays have arisen when special steps were required to compensate for problems with the data. The calibration of the ADCP's heading offset and velocity scaling using bottom-tracking procedure is very time consuming, but fortunately only needed to be performed when the transducer was reinstalled during dry-docking and when the AGPS was installed.

The scientific results from this project will appear elsewhere so only a typical section is shown here to illustrate the utility of ADCPs on VOS ships. Figure 12 shows the velocity vectors from the bin centered at $52-\mathrm{m}$ depth for the 24-26 September 1993 outbound transit. The most prominent feature is the Gulf Stream flowing east-northeast at about $215 \mathrm{~cm} \mathrm{~s}^{-1}$. The effect of the Gulf Stream on the ship track can be seen as an eastward deflection of about $30 \mathrm{~km}$ in the track. During this time period, a warm-core ring had just passed by the ship track and is clearly visible as an anticyclone north of the stream. Also notable is a broad region of southwestward flow between the Gulf Stream and Bermuda, which is believed to be part of the Gulf Stream recirculation gyre.

To give an idea of the vertical structure of the currents and ADCP depth penetration, Fig. 13 shows vertical sections of along-stream $\left(+\right.$ toward $\left.45^{\circ} \mathrm{T}\right)$ and crossstream ( + toward $135^{\circ} \mathrm{T}$ ) speeds from the $24-26 \mathrm{Sep}-$ tember cruise. The Gulf Stream axis is centered about $70.3^{\circ} \mathrm{W}$, and the sharp horizontal velocity gradient associated with the stream's north wall is located just to the northwest of the axis. The ring is centered about $71.7^{\circ} \mathrm{W}$, with core velocities of around $80 \mathrm{~cm} \mathrm{~s}^{-1}$ in its southeastern flank and $60 \mathrm{~cm} \mathrm{~s}^{-1}$ in its northwestern flank. Finally, it is interesting to note the $20-30 \mathrm{~cm} \mathrm{~s}^{-1}$ counterflow centered about $69.6^{\circ} \mathrm{W}$ and extending to almost 100-m depth. This counterflow separates the stream's core to the northwest from its weaker "shoulder" region to the southeast and is probably related to the upward-shoaling isopycnals often found to the 


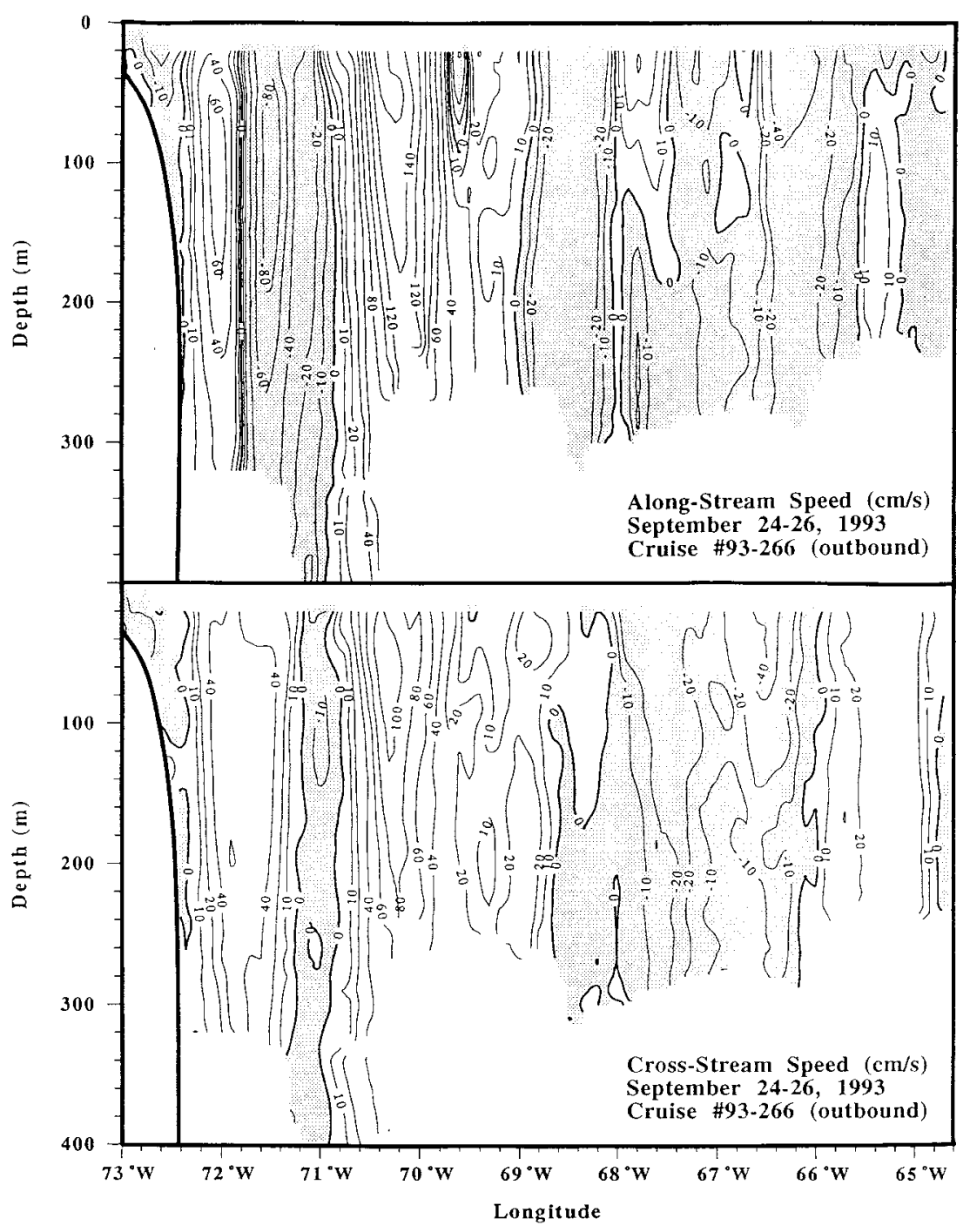

FIG. 13. Vertical sections of along- $\left(45^{\circ} \mathrm{T}\right)$ and cross- $\left(135^{\circ} \mathrm{T}\right)$ stream speeds for the transit shown in Fig. 12.

southeast of the stream's core (Halkin and Rossby 1985).

\section{Summary and conclusions}

This project has demonstrated that it is possible to use the ship-of-opportunity concept to acquire upperocean velocity data over large regions at a relatively modest cost. The development of the autonomous ADCP data collection system has made it possible to install and maintain relatively sophisticated instrumentation on volunteer observing ships without the onboard level of technical support associated with research vessels. More recently, it has been useful on regular research cruises in reducing the technicians' workload while maintaining high quality, continuous, and consistent datasets. The key elements in the implementation of the system on commercial vessels, however, are frequent and convenient access to the vessel, and the willingness and patience of the crew and owners to put up with the necessary modifications and troubleshooting that inevitably accompany the effort. The crew and owners of the CMV Oleander have shown much appreciated forbearance throughout this effort and have given a substantial amount of help and advice.

The following list summarizes the major items that have an impact on the installation of the ADCP (or any other electrical system) on a commercial vessel. The fact that some are obvious does not lessen their significance.

- Highly distributed system necessitated by the size and configuration of commercial ships.

- Inability to alter ship's systems to suit the installation 
or to alter operating methods because of absolute priority of the commercial purpose and cost of any downtime.

- Shape of commercial ship hulls and their speed seem to increase susceptibility to bubble sweep-down as do variations in load factor, causing variable data quality.

- Electrical complications are nontrivial, difficult to foresee, and difficult to diagnose, including the following: electromotive power transients, electromagnetic coupling between long parallel cables, electromagnetic coupling to signal cables, variations in electric voltage and frequency from shaft generators, increased ground loop susceptibility, and different grounding standards used on commercial vessels.

- Electrical isolation of distributed system parts can be implemented with optical isolators on data lines, noise isolation transformers, and online UPSs on power lines, and physical isolation of signal cables from other cables.

Distributed electronic systems located in an electrically noisy environment can be operated and maintained successfully if attention is given to electrical isolation of all its distributed parts. The CMV Oleander ADCP system was observed to have susceptibility to electromagnetic transients via four modes of noise coupling: 1) to the transducer cable, 2) to the serial wire that runs from the DAS PC on the bridge to the deck unit in the engine room, 3) from the ship's gyro repeater system to the ADCP gyro repeater and through to the NAV PC, and 4) from the ship's power through each UPS to the deck unit and PCs. The priority was to try to eliminate the cause of electrical noise interference. Failing that, attempts were made to reduce its effects in cases where it was not practical to eliminate the noise interference.

Electrical isolation can best be achieved by employing fiber optics to totally isolate the system components. This approach eliminates electrical noise such as common-and differential-mode noise since optical fiber is immune to electrical disturbances. It would not have been practical to replace the transducer cable with a fiber optic cable since this would have required a major redesign of the ADCP system. Therefore, in this case noise reduction techniques were the only alternative and gave excellent results since the cable tray allowed plenty of room to separate it from the others. Similarly, optically isolated serial data converters were employed on the line that traversed the engine room to connect the deck unit and the DAS PC.

An illustrative example is that noise coupled from the ship's gyro repeater to the ADCP compass repeater could not be eliminated at its source since the ship's gyrocompass system was outside our purview. Therefore, whatever noise was passed had to be accepted and its effects reduced. Operating the ADCP gyrocompass repeater on its own power supply, buffering its serial output with a serial optical isolator, and installing an AC line filter on its power supply seems to have con- tained the problem. Noise continues to be passed to the ADCP compass repeater but no longer affects other system components.

Entrained bubbles below the ship can cause severe degradation of ADCP signals and are the cause of significant data quality reduction in the CMV Oleander ADCP system. One possible approach to reducing their presence is to build a fairing around the sea chest opening to deflect the flow around it as was done after the fact on the RV Iselin (Leaman et al. 1989) and designed into the RV T. G. Thompson. While quite feasible, commercial ship owners are understandably reluctant to consider this option as it would add hydrodynamic drag and complicate dry-docking procedures.

Acknowledgments. It is a great pleasure to acknowledge the cooperation and support from everyone at the Bermuda Container Lines. In particular, we wish to thank Mr. Cor Teeuwen for his insightful support in getting the project started (even before the ship was completed in the yard) and his continuing support as the project evolved through its teething stages to a stable operation. Captains Vrolyk and van de Westeringh have been most helpful at all times. We particularly appreciate their alerting us whenever the ADCP system needed attention. The NOAA staff, and Mr. R. Benway, Mr. G. Strout, and Mr. W. Krug, in particular, are gratefully acknowledged for their help and assistance in maintaining the system and operating the XBT sampling program. We particularly wish to mention Dr. Eric Firing, and his staff Ms. J. Ranada and Mr. P. Caldwell, who have been most generous with their expertise whenever we needed help. We are most grateful to Ms. Sandy Fontana-Anderson, who has assisted us with her ADCP expertise in many ways. RD Instruments was very responsive in modifying the user exit code for this project. This program is supported by the NOAA Office of Global Programs under Contracts NA56GP0220 to the University of Rhode Island and NA92AANRG0064 to the Brookhaven National Laboratory.

\section{REFERENCES}

Ashtech Inc., 1994: 3DF three-dimensional direction finding system operating manual, Ashtech, 245 pp. [Available from Ashtech, Inc., 1170 Kifer Road, Sunnyvale, CA 94086.]

Benway, R. L., J. W. Jossi, K. P. Thomas, and J. R. Goulet, 1993: Variability of temperature and salinity in the Middle Atlantic Bight and Gulf of Maine. NOAA. Tech. Rep. NMFS 112, 110 pp. [Available from NOAA/NMFS, 28 Tarzwell Drive, Narragansett, RI 02882.]

Firing, E., J. Ramada, and P. Caldwell, 1995: Processing ADCP data with the CODAS software system version 3.1. Joint Institute for Marine and Atmospheric Research University of Hawaii, 212 pp. [Available from JIMAR/UH, 1000 Pope Road, Honolulu, HI 96822.]

Flagg, C. N., and S. L. Smith, 1989: On the use of the acoustic Doppler current profiler to measure zooplankton abundance. Deep-Sea Res., 36(3), 455-474.

Griffiths, G., 1994: Using 3DF GPS heading for improving underway ADCP data. J. Atmos. Oceanic Technol., 11, 1135-1143. 
Halkin, D., and T. Rossby, 1985: The structure and transport of the Gulf Stream at $73^{\circ}$ W. J. Phys. Oceanogr., 15, 1439-1452.

Iselin, C. O'D., 1940: Preliminary report on long-period variations in the transport of the Gulf Stream system. Pap. Phys. Oceanogr. Meteor., 8(1), 1-40.

King, B. A., and E. B. Cooper, 1994: GPS \& DGPS: Navigation tools for shipboard ADCPs. Sea Technol., 35(3), 10-15.

Leaman, K. D., R. J. Findley, and R. L. Hutchinson, 1989: ADCP hull-mount comparisons alleviate acoustic problems. Sea Technol., 30(9), 31-37.

Magnavox, 1991: MX 4200 PC controller user's guide. Magnavox Electronic Systems Company, 68 pp. [Available from Leica GPS, 23868 Hawthorne Boulevard, Torrance, CA 90505.]

New, A., 1992: Factors affecting the quality of shipboard acoustic Doppler current profiler data. Deep-Sea Res., 39, 1985-1996.
Pollard, R., and J. Reed, 1989: A method for calibrating ship-mounted acoustic Doppler profilers, and the limitations of gyrocompasses. J. Atmos. Oceanic Technol., 6, 859-865.

RD Instruments, 1991: Vessel mounted acoustic Doppler current profiler technical manual. RD Instruments, 299 pp. [Available from RDI, 9855 Business Park Avenue, San Diego, CA 92131.]

Sato, O., and T. Rossby, 1995: Seasonal and low frequency variations in dynamic height anomaly and transport of the Gulf Stream. Deep-Sea Res., 42, 149-164.

Tambs-Lyche, H., 1984: The continuous plankton recorder survey: The sampling program of the U. S. National Marine Fisheries Service. Ann. Biol. Information for the Year 1981, 38, 66-69.

Worthington, L. V., 1976: On the North Atlantic Circulation. The Johns Hopkins University Press, 110 pp. 